\title{
Putting patients first in the age of pharma
}

$\mathrm{P}$ atients come first in a new roadmap for ethical collaboration between health professionals and drug companies put forward by five global health organizations.

Signed by the World Medical Association, International Alliance of Patients' Organizations, International Council of Nurses, International Federation of Pharmaceutical Manufacturers and Associations and the International Pharmaceutical Federation on Jan. 13, the new Consensus Framework for Ethical Collaboration sets principles to govern interactions between patients, health professionals and drug companies.

At the top of the list: putting patients first. It's an old adage that bears repeating, particularly as shrinking budgets have made collaborations with industry a necessity for many health organizations in recent years, says Dr. Otmar Kloiber, secretary general of the World Medical Association.

"Treating patients is a team effort now," he explains. "Help from industry is welcomed as long as clinical independence is not jeopardized and patients get what is appropriate for them and not for third-party interests."

To that end, the framework calls on all parties to "ensure that collaboration between patients, health care professionals and pharmaceutical companies supports patients and their caregivers in making the best decision regarding their treatment."

The framework also sets guidelines for supporting ethical research and innovation, ensuring independence and ethical conduct, and promoting transparency and accountability. These guidelines include a rule that "no financial benefit or benefit in kind should be sought, offered, provided or accepted in exchange for prescribing, recommending, dispensing or administering medicine."

However, it is unclear to what extent the code will guide the actual policies of the signatory organizations, as the document includes a disclaimer that "it neither aims to be comprehensive nor does it constitute a single common policy of the organizations involved."

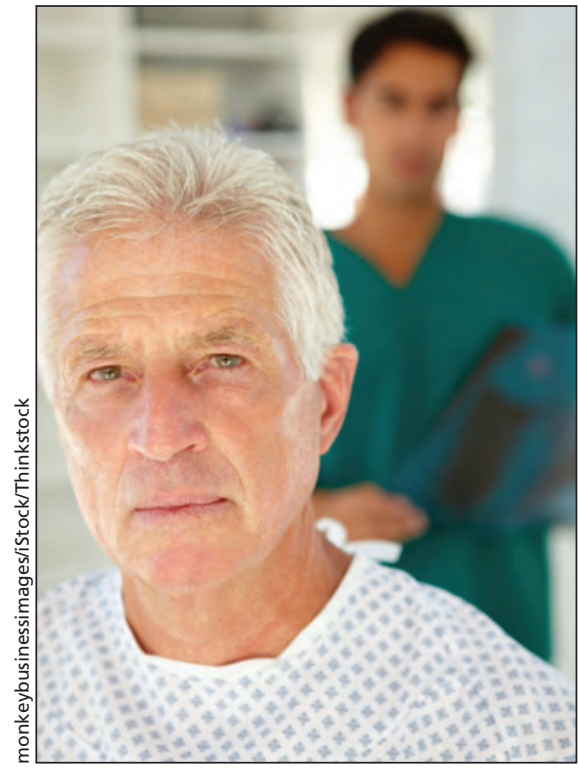

Patients must come first in health care professionals' dealings with drug companies, urge new ethical guidelines.

Rachel Seal-Jones, policy officer at the International Alliance of Patients' Organizations says the document is an "acknowledgement that they [drug companies] are stakeholders and that we do have to engage them, particularly in times of financial constraint."

According to Brenda Tu, president of the Ontario Patient Relations Association, budget constraints are often the foil of patient-centred initiatives. "And that's where you get into ethical dilemmas." However, some targeted initiatives have successfully carried off the balancing act.

An initiative led by Dr. Jeff Turnbull, chief physician at The Ottawa Hospital and past Canadian Medical Association president, provides medical care in the city's homeless shelters and is "effective and actually saves money," according to Turnbull.

The program delivers medical care in the community; care that otherwise would have required an emergency department visit or even hospitalization, he explains. "We took health care to them, on their terms, to identify their specific needs." - Michael Fralick, CMAJ

CMAJ 2014. DOI:10.1503/cmaj.109-4716 